\title{
EXPRORASI METODE PENGOBATAN TRADISIONAL OLEH PARA PENGOBAT TRADISIONAL DI WILAYAH KARESIDENAN SURAKARTA
}

\author{
Indarto, Agus Kirwanto \\ Kementerian Kesehatan Politeknik Kesehatan Surakarta Jurusan Jamu
}

\begin{abstract}
Traditional Medicine Method, Treatment Method, Traditional Medicinal Herb Type, Plant Type. The empirical traditional medicine (battra) using herbs and physical skills to date is still in demand by the people in the Surakarta Residency area, reflected the increasing number of traditional healers who are currently performing traditional health practices, since they have been protected by Law no. 36 of 2014, which regulates the health of personnel, in article 11, paragraph 13, classifies traditional empirical health workers consisting of traditional herbal medicine and traditional health skills. It makes public confidence is still high with traditional medicine therefore need to be disclosed about the phenomenon of methods of traditional healers in the treatment of the community. The purpose of this study is to find out how batras perform detection of patient diseases, to know the method of treatment performed battra in treating patients, know the composition of the herb used for the treatment and know what medicinal plants used to treat patients. Qualitative research type with an explorative approach design with data collection method of indepth interviews and observation of 18 informants, using triangulation method, source and theory as test of data validity. The results of the study that battra use various ways to detect the patient's illness is bengan ask a complaint, history of the disease as well as menfatkan diognosa doctors are known from patients and check using aids such as reflection equipment, tensimeter, digital cameras and laptops to check iridology. there are 2 methods used battra treat the patient that is using herb/ herbal concoction and physical skill, among others cupping of reflexology, rukyah and therapy energi.didapatkan 23 type of concoction used to treat patient, and 81 medicinal plants used for patient's herb treatment.
\end{abstract}

Keywords: Traditional Medicine Method, Treatment Method, Traditional Medicinal Herb, Plant Type

\begin{abstract}
Abstrak : Metode Pengobatan Tradisional, Cara Pengobatan, Jenis Ramuan Obat Tradisional, Jenis Tanaman. Pengobatan tradisional (battra) empirik yang menggunakan ramuan maupun ketrampilan fisik sampai saat ini masih diminati masyarakat di wilayah karesidenan surakarta tercermin semakin banyaknya pengobat tradisional yang saat ini melakukan praktek kesehatan tradisional, karena telah dilindungi undang undang UU No. 36 Tahun 2014 yang mengatur tentang ketenagaan Kesehatan, pada pasal 11 ayat 13 jenis mengklasifikasikan tenaga kesehatan tradisional empiris terdiri dari tenaga kesehatan tradisional ramuan dan tenaga kesehatan tradisional ketrampilan. hal tersebut membuat kepercayaan masyarakat masih tinggi dengan pengobatan tradisional oleh karena itu perlu diungkap tentang fenomena metode para pengobat tradisional dalam melakukan pengobatan pada masyarakat. Tujuan
\end{abstract}


penelitian ini untuk mengetahui bagaimana para battra melakukan deteksi gangguan penyakit pasien, untuk mengetahui metode pengobatan yang dilakukan battra dalam mengobati pasien, mengetahui komposisi ramuan yang dipakai untuk pengobatan serta mengetahui tanaman obat apa yang digunakan untuk mengobati pasien.jenis penelitian kualitatif dengan disain pendekatan exploratif dengan metode pengambilan data indepth interviews dan observasi terhadap 18 informan, menggunakan trianggulasi metode, sumber dan teori sebagai uji keabsahan data. Hasil penelitian bahwa para battra menggunakan berbagai cara untuk mendeteksi penyakit pasien yaitu bengan bertanya keluhan, riwayat penyakit serta memanfatkan diognosa dokter yang diketahui dari pasien serta memeriksa memakai alat bantu seperti alat refleksi, tensimeter, kamera digital dan laptop untuk memeriksa iridologi. ada 2 metode yang digunakan battra mengobati pasien yaitu menggunakan ramuan jamu/ herbal serta ketrampilan fisik, antara lain bekam pijat refleksi,rukyah dan terapi energi.didapatkan 23 jenis ramuan yang dipakai untuk mengobati pasien, serta 81 tanaman obat yang digunakan untuk ramuan pengobatan pasien.

Kata Kunci : Metode Pengobatan Tradisional, Cara Pengobatan, Jenis Ramuan Obat Tradisional, Jenis Tanaman

\section{PENDAHULUAN}

Pengobatan tradisional banyak mendapatkan perhatian baik di kalangan masyarakat maupun pakar di bidang kesehatan, karena kenyataannya di masyarakat pengobatan tradisional ini masih hidup dan berdampingan dengan pengobatan modern selain itu pengobatan tradisional dapat menjadi alternatif dalam pemulihan kesehatan manusia (Sudardi B., 2012). Pengobatan tradisional merupakan fenomena social budaya yang telah menyatu dalam kehidupan masyarakat dan digunakan untuk berbagai macam penyakit baik di desa maupun di kota-kota besar. Dengan diundangkanya UU No. 36 Tahun 2014 yang mengatur tentang Ketenagaan Kesehatan pada pasal 11 ayat 13 jenis mengklasifikasikan tenaga kesehatan tradisional yang terdiri dari tenaga kesehatan tradisional ramuan dan tenaga kesehatan tradisional ketrampilan. Juga diterangkan Pasal 1 ayat $16 \mathrm{UU}$ Kesehatan menetapkan bahwa pengobatan tradisional adalah pengobatan dan/ atau perawatan dengan cara dan obat yang mengacu pada pengalaman dan keterampilan turun temurun secara empiris yang dapat dipertanggungjawabkan dan diterapkan sesuai dengan norma yang berlaku di masyarakat. Pengobatan tradisional yang dipakai pada jaman dahulu dengan beraneka ragam dari tanaman obat, jampejampe atau do'a, primbon dan masih banyak lagi, dan sejak dahulu pengobatan penduduk Indonesia sudah popular dengan jamu. Pengobatan warisan dari nenek mulyang ini sampai saat ini tetap masih banyak diminati masyarakat dan semakin berkembang variasinya. Masyarakat jawa khususnya jawa tengah yang menggunakan pengobatan dengan cara tradisional cenderung meningkat baik yang menggunakan ramuan jamu sebagai obat maupun keterapian fisik yang mendukungnya untuk kesehatanya. Terbukti saat ini banyak bermunculan klinik/ rumah herbal atau pegobatan tradisional yang berkembang dimana 
mana, seperti rumah bekam, rumah sehat refleksi, rumah akupungtur dan lainya dan setiap klinik ramai dikunjungi klien untuk mendapatkan terapi. Seperti yang tampak pada pengobat tradisional $\mathrm{Bp} \mathrm{Al}$ rata- rata mereka dikunjungi 5-10 klien perhari, di Kab Karanganyar rumah pengobatan Iklas dan Alya tama dan di Kab Klaten rumah pengobatan tradisional bpk $\mathrm{SH}$ dan dan rumah pengobatan bpk TM rata rata dikunjungi 10 - 20 klien perhari, hal ini menandakan masyarakat masih percaya dengan para pengobat tradisional yang menggunakan ramuan dan terapi fisik, oleh karena itu perlu diungkap tentang fenomena apa yang dilakukan para pengobat tradisional untuk melakukan deteksi gangguan kesehatan pada klien, metode apa yang digunakan untuk melakukan pengobatan tradisional, jenis ramuan obat apa yang digunakan oleh pengobat tradisional, serta tumbuhan obat yang digunakan dalam memberikan pelayanan kesehatan tradisional

\section{METODE PENELITIAN}

Jenis penelitian adalah kualitatif dengan desain pendekatan ekplorasi untuk mengungkap bagaimana cara para pengobat tradisional melaksanakan deteksi gangguan kesehatan klien, metode apa yang digunakan dalam pengobatan, jenis ramuan dan tumbuhan obat yang digunakan serta cara mereka membuat ramuan dalam pelayanan kesehatan tradisional. Untuk mendapatkan derajat kepercayaan data digunakan Triangulasi teknik, dan trianggulasi sumber sedangkan langkah analisa data menggunakan model Miles and Huberman dengan empat langkah yang meliputi: Pengumpulan data, dengan wawancara mendalam dan observasi., Reduksi data pemberian kodekode dan dikelompokkan dalam satu kategori., Penyajian data dengan uraian singkat, bagan, hubungan antar kategori., Verifikasi dan analisis serta penarikan kesimpulan

\section{HASIL PENELITIAN}

Informan dalam penelitian ini adalah para pengobat tradisional yang berada diwilayah karesidenan Surakarta yang meliputi 7 Kabupaten dengan jumlah 18 orang. dan telah memiliki pengalaman pengobatan diatas 10 thn dan sampai saat ini masih memberikan pengobatan tradisional, pasien yang datang berobat setiap harinya antara 2 sampi 15 pasien adapun karakteristik informal dapat dilihat pada tabel 1 dibawah ini :

\section{Tabel 1}

Karakteristik Informan Pengobat Tradisional Di Wilayah Karesidenan Surakarta

\begin{tabular}{l|c|c|c|c|c|c|c}
\hline \multicolumn{2}{c|}{$\begin{array}{c}\text { Usia } \\
\text { Informan }\end{array}$} & \multicolumn{2}{c|}{$\begin{array}{c}\text { Pendidikan } \\
\text { Umum } \\
\text { Informan }\end{array}$} & \multicolumn{2}{c|}{$\begin{array}{l}\text { Lama } \\
\text { pengalaman } \\
\text { Mengobati } \\
\text { Informan }\end{array}$} & \multicolumn{2}{|c}{$\begin{array}{c}\text { Jenis } \\
\text { Kelamin } \\
\text { Informan }\end{array}$} \\
\hline $\begin{array}{l}25- \\
50 \\
\text { thn }\end{array}$ & $\begin{array}{l}51- \\
75 \\
\text { thn }\end{array}$ & $\begin{array}{l}\text { Pend } \\
\text { dasar }\end{array}$ & $\begin{array}{l}\text { Pend } \\
\text { tinggi }\end{array}$ & $\begin{array}{l}6-10 \\
\text { th }\end{array}$ & $\begin{array}{l}11- \\
25 \text { th }\end{array}$ & $\begin{array}{l}\text { laki } \\
- \\
\text { laki }\end{array}$ & $\begin{array}{l}\text { peremp } \\
\text { uan }\end{array}$ \\
\hline 2 or & $\begin{array}{c}16 \\
\text { or }\end{array}$ & 12 & 6 or & 0 & 18 & 16 & 2 \\
\hline
\end{tabular}

\section{Cara pengobat tradisional mendekteksi gangguan kesehatan pasien}

Sebelum para pengobat tradisional memberikan terapi/ pengobatan pada para pasien, para pengobat tradisional melakukan pendeteksian gangguan penyakit yang terjadi pada diri pasien melalui berbagai cara antara lain dengan : bertanya (anamnesa) pada pasien dan keluarga yang mengantarnya, dan bertanya tentang identintas, keluhan yang dirasakan pasien atau penyakit pasien, 
lamanya sakit, sudah berobat kemanan serta pertanyaan lain yang terkait. Sebagian besar para pengobat tradisional juga melakukan deteksi penyakit melalui pemeriksaan fisik pasien, dengan cara memegang, memijat, menekan tempat yang sakit, bahkan melakukan totok darah di leher pasien serta ada yang memeriksa menggunakan alat pemeriksaan tertentu seperti tensi, termometer, kamera foto untuk pemeriksaan iridologi dan scrlerodologi, Ada pengobat tradisional yang mendeteksi kondisi pasien dengan cara melihat kesehatan atau penyakit pasien dengan melihat telapak tangan pasien, melihat anda tanda sakit ditangan, menggunakan weton atau hitungan hari menurut hitungan jawa untuk melihat gejala penyakitnya, ada yang menggunakan cara spiritual melalui persepsi dan mata hatinya serta ada yang menggunakan energi dirinya untuk melihat mendeteksi gangguan pada pasien. Lebih lengkapnya dapat dilihat dari tabel 2 dibawah ini :

\section{Tabel 2}

Cara Pengobat Tradisional Mendeteksi Penyakit Pasien (Tanpa Alat Bantu)

\begin{tabular}{|c|c|c|c|c|c|}
\hline \multicolumn{6}{|c|}{ Cara Pengobat Tradisional Untuk Deteksi Penyakit Pasien Tanpa Alat Bantu } \\
\hline Bertanya & $\begin{array}{l}\text { Memeriksa } \\
\text { tempat yang } \\
\text { saki }\end{array}$ & Melihat & Menotok & $\begin{array}{l}\text { Menggunakan } \\
\text { energi dirinya }\end{array}$ & $\begin{array}{l}\text { cara } \\
\text { spiritual }\end{array}$ \\
\hline $\begin{array}{l}\text {-indentitas } \\
\text {-keluhan } \\
\text {-riwayat } \\
\text { sakit dan } \\
\text { lamanya } \\
\text { sakit } \\
\text {-diognosa } \\
\text { dr /mantri } \\
\text { penyakit } \\
\text { nya apa }\end{array}$ & $\begin{array}{l}\text {-menekan } \\
\text {-mengurut } \\
\text {-memijat } \\
\text { tempat } \\
\text { tertentu } \\
\text {-memeriksa } \\
\text { nadi }\end{array}$ & $\begin{array}{l}\text {-wajah } \\
\text { dan } \\
\text { mata } \\
\text {-keadaan } \\
\text { pasien } \\
\text {-melihat } \\
\text { gejala di } \\
\text { telapak } \\
\text { tangan } \\
\text {-tanda } \\
\text { ditangan } \\
\text {-warna } \\
\text { kulit }\end{array}$ & $\begin{array}{l}\text {-menotok } \\
\text { jalan darah } \\
\text { leber } \\
\text {-titik } \\
\text { akupresuer }\end{array}$ & $\begin{array}{l}\text {-menggunakan } \\
\text { energi dari } \\
\text { tangan } \\
\text {-kinestetik }\end{array}$ & $\begin{array}{l}\text {-melihat } \\
\text { dengan } \\
\text { mata hati }\end{array}$ \\
\hline
\end{tabular}

Tabel 3

Cara Yang Dilakukan Battra Untuk Mendeteksi Penyakit Dengan Bantuan Alat

\begin{tabular}{|c|c|c|c|}
\hline Alat kesehatan & Alat kayu & $\begin{array}{l}\text { Alat } \\
\text { elektronik }\end{array}$ & $\begin{array}{l}\text { Memeriksak } \\
\text { an di lab }\end{array}$ \\
\hline $\begin{array}{l}\text {-Tensi } \\
\text {-dan stetoskop } \\
\text {-termometer }\end{array}$ & $\begin{array}{l}\text {-alat refleksi } \\
\text {-alat totok dari } \\
\text { kayu }\end{array}$ & $\begin{array}{l}\text {-kamera } \\
\text { digital } \\
\text { untuk } \\
\text { memfoto } \\
\text { Iris masta } \\
\text { pasien } \\
\text {-laptop yang } \\
\text { sudah } \\
\text { teraplikasi } \\
\text { dengan } \\
\text { terapi } \\
\text { herbalnya }\end{array}$ & $\begin{array}{l}\text {-mengirim } \\
\text { pasien untuk } \\
\text { diperiksa di } \\
\text { prodia }\end{array}$ \\
\hline
\end{tabular}

\section{Metode Pengobatan yang dipakai para pengobat tradisional (Battra)}

Metode pengobatan yang dipakai pengobat tradisional meliputi :1). Memberi terapi ramuan jamu atau herbal dan 2). Dengan cara memberikan terapi fisik untuk membantu kesembuhan pasien. Didapatkan 23 jenis ramuan jamu dari hasil penelitian seluruh pengobat tradisional yang diteliti, Tabel 6 menerangkan jenis ramuan (R/) untuk gangguan penyakit (Asam Urat). Komposisi ramuan yang dimiliki R/1 inf. INW (artinya Ramuan asam urat no urut 1dari informan bernama INW, dengan komposisi seperti yang tertera pada tabel 4. 
Tabel 4

Jenis Ramuan Sediaan Jamu Untuk Mengobati Asam Urat Yang Diberikan Para Pengobat Tradisional Untuk Mengobati Pasien

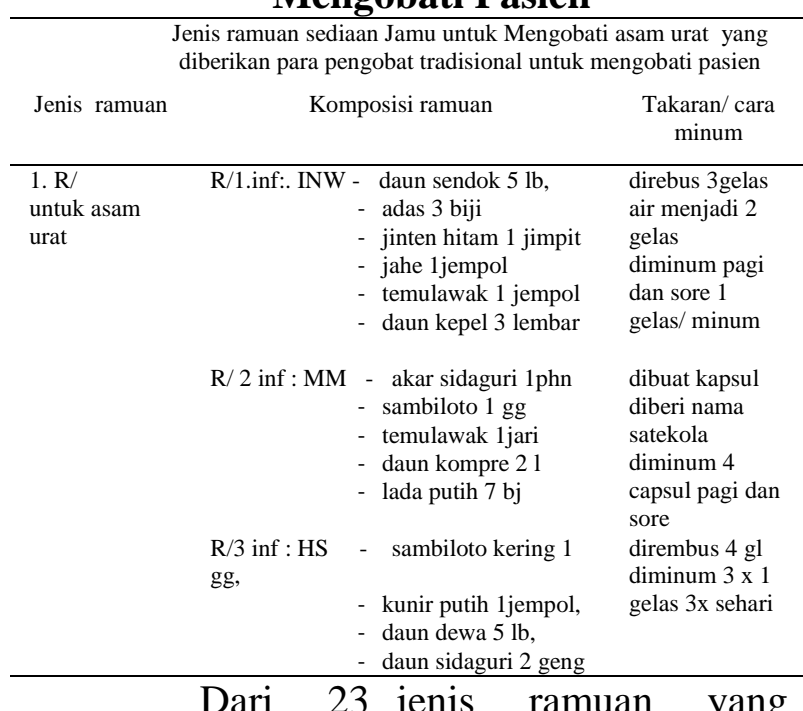
dipakai para pengobat tradisional untuk mengobati pasien, diperoleh 6 variasi isi ramuan yang memiliki kesamaan, lebih jelasnya dapat dilihat pada tabel 5 .

\section{Tabel 5}

\begin{tabular}{|c|c|c|c|}
\hline No & $\begin{array}{c}\text { Nama } \\
\text { Ramuan }\end{array}$ & $\begin{array}{c}\text { Jumlah } \\
\text { Variasi } \\
\text { Ramuan } \\
\text { Yang } \\
\text { Sama } \\
\text { Komp }\end{array}$ & $\begin{array}{c}\text { Kesamaan Bahan } \\
\text { Ramuan }\end{array}$ \\
\hline 1 & $\begin{array}{l}\text { untuk asam } \\
\text { urat }\end{array}$ & $\begin{array}{c}5 \\
\text { ramuan }\end{array}$ & $\begin{array}{l}\text { sidaguri,temulawak,samb } \\
\text { iloto }\end{array}$ \\
\hline 2 & $\begin{array}{l}\text { untuk } \\
\text { kolesterol }\end{array}$ & $\begin{array}{c}4 \\
\text { ramuan }\end{array}$ & $\begin{array}{l}\text { bawang madu dlm } \\
\text { fermentasi }\end{array}$ \\
\hline 3 & $\begin{array}{l}\text { untuk } \\
\text { hipertensi }\end{array}$ & $\begin{array}{c}2 \\
\text { ramuan }\end{array}$ & $\begin{array}{l}\text { pegagan, kumis kucing, } \\
\text { tempuyung }\end{array}$ \\
\hline 4 & $\begin{array}{l}\text { untuk } \\
\text { diabitus } \\
\text { militus }\end{array}$ & $\begin{array}{c}6 \\
\text { ramuan }\end{array}$ & $\begin{array}{l}\text { dandang gendis, daun } \\
\text { mimbo, kumis kucing, } \\
\text { brotowali, duwet }\end{array}$ \\
\hline 5 & $\begin{array}{l}\text { untuk } \\
\text { kanker/tumor }\end{array}$ & $\begin{array}{c}5 \\
\text { ramuan }\end{array}$ & $\begin{array}{l}\text { kunyit putih, daun benalu, } \\
\text { daun sirih, temulawak, } \\
\text { keladi tikus }\end{array}$ \\
\hline 6 & $\begin{array}{l}\text { untuk } \\
\text { peningkatan } \\
\text { stamina }\end{array}$ & $\begin{array}{c}5 \\
\text { ramuan }\end{array}$ & $\begin{array}{l}\text { jahe merah, purwoceng, } \\
\text { kuning telor, lada hitam, } \\
\text { cabe jawa,madu, pasak } \\
\text { bumi }\end{array}$ \\
\hline
\end{tabular}

Sediaan ramuan jamu yang diberikan untuk mengobati pasien setiap pengobat tradisional memiliki bentuk yang bervariasi dan berbeda beda, ada yang berbentuk simplisia, ada yang dibuat serbuk dalam capsul, ada juga yang dibuat fermentasi disajikan dalam bentuk cairan dan ada yang berbentuk kemasan wedang seduan. Lebih lenkapnya dapat dilihat pada tabel 6 .

Tabel 6

\section{Bentuk Sediaan Ramuan Jamu/ Herbal} Yang Diberikan Pada Pasien

\begin{tabular}{|c|c|c|c|}
\hline \multicolumn{4}{|c|}{$\begin{array}{c}\text { Bentuk Sediaan Ramuan Sediaan Jamu/ Herbal Yang } \\
\text { Diberikan Pada Pasien }\end{array}$} \\
\hline Ramuan & Bentuk sediaan & $\begin{array}{l}\text { Penyajian } \\
\text { ke pasien }\end{array}$ & Keterangan \\
\hline $\begin{array}{l}\text { 1. jamu } \\
\text { /herbal }\end{array}$ & $\begin{array}{ll}\text { a. } & \begin{array}{l}\text { Godokan/ } \\
\text { seduan }\end{array} \\
\text { b. } & \text { simplisia } \\
\text { c. } & \text { bubuk } \\
& \text { dalam } \\
& \text { kapsul } \\
\text { d. } & \text { ektrak } \\
& \text { dalam } \\
& \text { kapsul } \\
\text { e. } & \text { serbuk } \\
\text { murni } \\
\text { f. } & \text { wedang } \\
& \text { jamu }\end{array}$ & $\begin{array}{l}\text { dalam } \\
\text { gelas dan } \\
\text { botol } \\
\text { dalam } \\
\text { kemasan } \\
\text { plastik } \\
\text { kapsul } \\
\text { berwarna } \\
\text { warni } \\
\text { ektrak } \\
\text { kapsul } \\
\text { dalam } \\
\text { kemasan } \\
\text { plastik } \\
\text { plastik } \\
\text { aluminium } \\
\text { foil }\end{array}$ & $\begin{array}{l}\text { dibuat } \\
\text { sendiri } \\
\text { dibuat } \\
\text { /membeli } \\
\text { dibuat/ } \\
\text { membeli } \\
\text { dibuat/ } \\
\text { membeli } \\
\text { membeli } \\
\text { dibuat } \\
\text { sendiri }\end{array}$ \\
\hline $\begin{array}{l}\text { 2. jamu } \\
\text { fermentasi }\end{array}$ & cair & $\begin{array}{l}\text { dalam } \\
\text { botol } \\
\text { plastik }\end{array}$ & $\begin{array}{l}\text { dibuat } \\
\text { sendiri }\end{array}$ \\
\hline 3. madu & $\begin{array}{ll}\text { a. } & \text { madu } \\
& \text { murni } \\
\text { b. } & \text { madu } \\
& \text { fermenta } \\
& \text { si jamur } \\
& \text { /bawang }\end{array}$ & $\begin{array}{l}\text { dalam } \\
\text { botol kaca } \\
60 \mathrm{ml} 100 \\
\mathrm{ml} 630 \\
\text { dalam } \\
\text { botol kaca } \\
60 \mathrm{ml}\end{array}$ & $\begin{array}{l}\text { dibuat/ } \\
\text { membeli } \\
\text { dibuat }\end{array}$ \\
\hline $\begin{array}{l}\text { 4.sirup } \\
\text { herbal }\end{array}$ & sirup cair & $\begin{array}{l}\text { kemasan } \\
\text { botol } 630 \\
\mathrm{ml}\end{array}$ & membeli \\
\hline $\begin{array}{l}5 . \text { teh } \\
\text { herbal }\end{array}$ & teh kering & $\begin{array}{l}\text { kemasan } \\
\text { teh celup }\end{array}$ & $\begin{array}{l}\text { dibuat } \\
\text { sendiri }\end{array}$ \\
\hline $\begin{array}{l}\text { 6. herbal } \\
\text { instan }\end{array}$ & instan serbuk & $\begin{array}{l}\text { kemasan } \\
\text { saset dan } \\
\text { botol }\end{array}$ & $\begin{array}{l}\text { dibuat } \\
\text { sendiri }\end{array}$ \\
\hline $\begin{array}{l}7 . \\
\text { lulur/boreh }\end{array}$ & bubuk dan cair & $\begin{array}{l}\text { bubuk dan } \\
\text { cair }\end{array}$ & $\begin{array}{l}\text { dibuat } \\
\text { sendiri }\end{array}$ \\
\hline & bol & mato & yang \\
\hline
\end{tabular}


dalam usaha membantu penyembuhan pasien sebagian besar informan mengkombinasikan dengan metode terapi fisik seperti bekam, akupresur pijat refleksi, totok darah dan lainya ada juga yang mengkombinasi dengan metode energi dan spiritual lebih lengkapnya kita lihat di tabel 7

\section{Tabel 7}

Metode Pengobatan Fisik Yang

Dilakukan Para Pengobat Tradisional

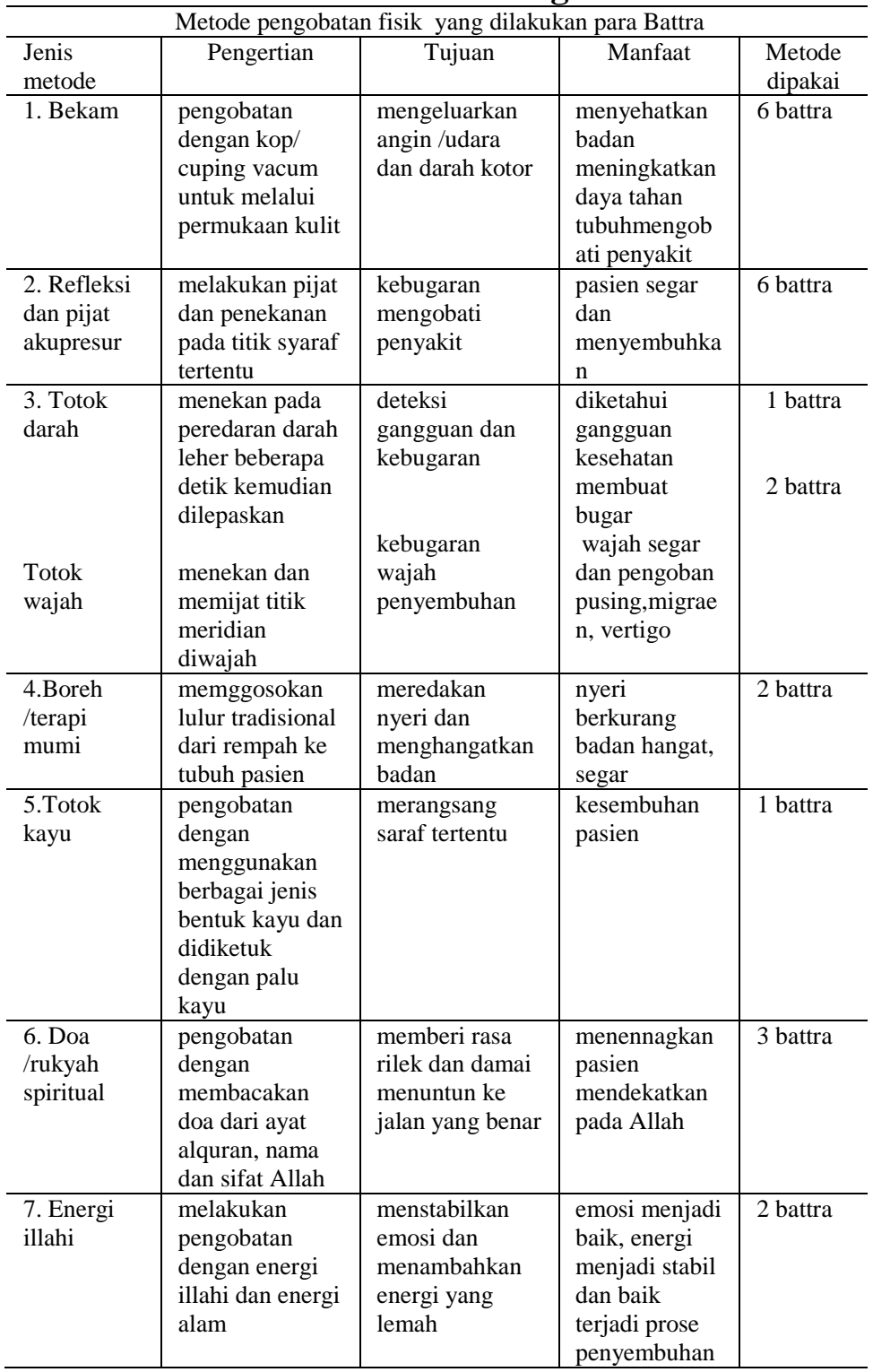

\section{Tanaman obat yang digunakan para pengobat tradisional}

Para pengobat tradisional yang melakukan pengobatan dengan jamu/ herbal menggunakan berbagai jenis tanaman obat, baik tanaman obat yang ditanam disekitar halaman, di kebun, sengaja dibudidayakan, ada juga yang menggunakan tanaman obat dengan cara membeli di pasar, ditoko jamu ada pula yang membeli di para petani sekitar tawangmangu dalam bentuk simplisia atau sudah dalam bentuk serbuk jadi. Jenis tanaman obat yang digunakan para pengobat tradisional ada yang menggunakan daun sebagai obat tradisional dan ada yang berupa batang, akar, bunga, biji serta kulitnya. Penggunaanya ada yang tunggal seperti daun ungu, kebanyakan penggunaanya diramu dengan berbagai daun lain atau biji, akar, kulit, batang serta bahan jamu lainya seperti madu, gula, sirup, dan bahan ramuan lainya. Hal tersebut akan disajikan dalam pengelompokan daun dari jenis tanaman herba, jenis tanaman pohon, serta jenis tanaman rambat, pada tabel 8 dibawah ini. 
Tabel 8

\begin{tabular}{|c|c|c|c|}
\hline & $\begin{array}{l}\text { Dari Tan: } \\
\text { faat Yang }\end{array}$ & $\begin{array}{l}\text { an Jenis H } \\
\text { Pakai Par }\end{array}$ & $\begin{array}{l}\text { a Dan } \\
\text { attra }\end{array}$ \\
\hline & dari tanaman je & herba dan manf & \\
\hline Daun & Manfaat & Daun & Manfaat \\
\hline $\begin{array}{ll}\text { 1. } & \begin{array}{l}\text { Rumput } \\
\text { mutiara }\end{array} \\
\text { 2. } & \text { Meniran } \\
\text { 3. } & \text { Jamur } \\
\text { lingsi } \\
\text { 4. } & \text { Komfrey } \\
\text { 5. } & \text { Sambun } \\
\text { g njowo } \\
\text { 6. } & \text { Seledri } \\
\text { 7. } & \text { Pegagan } \\
\text { 8. } & \text { Purwoce } \\
\text { ng } \\
\text { 9. } & \text { Tapak } \\
\text { liman } \\
\text { 10. } & \text { Tempuy } \\
& \text { ung } \\
\text { 11. } & \text { Kumis } \\
\text { kucing } \\
\text { 12. } & \begin{array}{l}\text { Dandang } \\
\text { gendis }\end{array}\end{array}$ & $\begin{array}{l}\text { peningkatan kes } \\
\text { peningkatan kes } \\
\text { peningkatan kes } \\
\text { menjaga TD } \\
\text { anti hipertensi } \\
\text { anti hipertensi } \\
\text { pelancar darah } \\
\text { kejantanan } \\
\text { penguat ginjal } \\
\text { penguat ginjal } \\
\text { penguat ginjal } \\
\text { DM }\end{array}$ & $\begin{array}{l}\text { 13. Insulin } \\
\text { 14. Baru cina } \\
\text { 15. Daun mint } \\
\text { 16. Sembung } \\
\text { 17. Anting anti } \\
\text { 18. Serai wangi } \\
\text { 19. Kemladian } \\
\text { 20. Daruju } \\
\text { 21. Daun dewa } \\
\text { 22. Daun } \\
\text { sendok } \\
\text { 23. Sidaguri } \\
\text { 24. Daun encok }\end{array}$ & $\begin{array}{l}\text { DM } \\
\text { kesuburan } \\
\text { penyegar \& } \\
\text { kembung } \\
\text { kembung } \\
\text { desentri \& } \\
\text { memar } \\
\text { penghangat } \\
\& \text { harum } \\
\text { tumor dan } \\
\text { kangker } \\
\text { tomor } \\
\text { /kangker } \\
\text { tumor } \\
\text { /kangker } \\
\text { asam urat } \\
\text { asam urat } \\
\text { rematik }\end{array}$ \\
\hline
\end{tabular}

Jenis tanaman pohon yang memiliki kasiat obat dan dipakai oleh para battra dapat dilihat pada tabel 9 dibawah ini.

Tabel 9

Daun Dari Tanaman Jenis Pohon Dan Manfaatnya

Daun dari tanaman Jenis pohon dan manfat

\begin{tabular}{|c|c|c|c|c|}
\hline Daun & Manfaat & & Daun & Manfaat \\
\hline 1. Salam & DM dan koles & 10. & Jati & hipertensi \\
\hline 2. Mimbo & DM & & belanda & kolesterol \\
\hline 3. Kelor & sakit kuning & 11. & Daun teh & hipertensi \\
\hline 4. Kepel & asam urat & 12. & Jati cina & pengurus badan \\
\hline 5. Puring & cacingan & 13. & Kemuning & penurunan $\mathrm{BB}$ \\
\hline 6. Daun & Penambah ASI & 14. & Jeruk nipis & amandel dan kes \\
\hline sukun & penambah ASI & 15. & Senggugu & batuk dan gurah \\
\hline 7. Daun Turi & ambeyen & 16. & Mimbo & tumor /DM \\
\hline 8. Daun ungu & diarea & 17. & Daun & desentri amuba \\
\hline 9. Daun & & & delima & kesuburan \\
\hline jambu biji & & 18. & $\begin{array}{l}\text { Daun } \\
\text { dadap }\end{array}$ & \\
\hline
\end{tabular}

Tanaman yang merambat dipakai untuk pengobatan oleh para battra antara lain tanaman saga rambat, sirih, binahong dan lainya yang memiliki kasiat obat dapat lihat padatabel 10 dibawah ini.
Tabel 10

\section{Jenis Daun Dari Tanaman Rambat} Dan Manfat

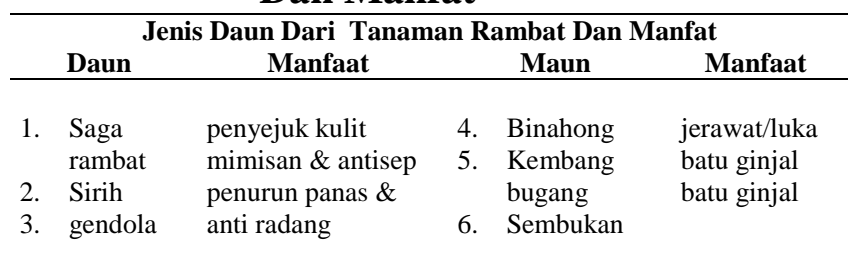

Selain tananam daun para battra juga menggunakan bagian tanaman dari rimpang antara lain: jahe, kunyit, temulawak, lengkuas dan lainya., dari batang dan kulit seperti kayu secang, kayu manis kulit delima dan lainya., dari bunga dan buahnya antara lain : buah makutodewo, jabe jawa,belimbing, buah duwet dan lainya., dari akar dan ubi-ubian antara lain: ubi rumput teki, ubi bawang, ubi bidara upas dan akar alang alang dan pasak bumi serta ada juga yang menggunakan biji antara lain: biji adas, biji jinten hitam dan kapulogo. Lihat tabel 11.

\section{Tabel 11}

\section{Jenis Tanaman Selain Daun Yang Di} Pakai Battra

Jenis tanaman selain daun yang di pakai pengobat tradisional diwilayah karesidenan Surakarta

\begin{tabular}{|c|c|c|c|c|}
\hline Rimpang & $\begin{array}{c}\text { Batang dan } \\
\text { kulit }\end{array}$ & $\begin{array}{c}\text { Bunga dan } \\
\text { Buah }\end{array}$ & Akar dan Ubi & Biji \\
\hline $\begin{array}{ll}\text { 1. } & \text { jahe } \\
\text { 2. } & \text { kunyit } \\
\text { 3. } & \text { kunyit } \\
& \text { putih } \\
\text { 4. } & \text { temulaw } \\
& \text { ak } \\
\text { 5. } & \text { temu } \\
& \text { ireng } \\
6 . & \text { temu } \\
& \text { mangga } \\
\text { 7. } & \text { bangkle } \\
\text { 8. } & \text { lengkua } \\
& \text { s } \\
9 . & \text { kencur } \\
\text { 10. } & 10 \\
& \text { kunci } \\
& \text { pepet }\end{array}$ & $\begin{array}{l}\text { 1. secang } \\
2 . \text { kayu } \\
\text { manis } \\
\text { 3. kayu } \\
\text { rapet } \\
\text { 4. kulit } \\
\text { delima } \\
\text { 5.kulitmang } \\
\text { gis } \\
\text { 6.cengkeh }\end{array}$ & $\begin{array}{l}\text { 1. makuto dewo } \\
\text { 2. belimbing } \\
\text { 3. pekak } \\
\text { 4. duwet } \\
\text { 5. cabe jawa } \\
\text { 6.kemukus }\end{array}$ & $\begin{array}{l}\text { 1. teki } \\
\text { 2.keladi tikus } \\
\text { 3.bidara upas } \\
\text { 4 bawang } \\
\text { putih } \\
\text { 5. B. dayak } \\
\text { 6.pasak bumi } \\
\text { 7...alang alang }\end{array}$ & $\begin{array}{l}\text { 1. lada } \\
\text { 2. adas } \\
\text { 3. jinten } \\
\text { hitam } \\
\text { 4. kapulogo }\end{array}$ \\
\hline
\end{tabular}




\section{PEMBAHASAN}

Pemeriksaan fisik merupakan suatu cara untuk mengetahui gejala atau masalah kesehatan yang dialami oleh pasien,pemeriksaan fisik bertujuan untuk mengumpulkan data tentang kesehatan pasien, menambah informasi, menyangkal data yang diperoleh dari riwayat paien, mengidentifikasi masalah pasien serta menilai perubahan status pasien. Hal tersebut juga sesui pendapat Reeder,SJ.et al (2014) pengkajian yang dilakukan perawat untuk mengenal kondisi dan situasi berdasarkan informasi yang dikumpulkan membentuk pangkalan data yang penting bertujuan untuk mengidentifikasi dan memperoleh data mengenai kebutuhan pasien yang memungkinkan perawat, pasien keluarga mengenali masalah pasien. Ada batra yang menggunakan pemeriksaan dengan tensi dan stetoskop sebaiknya ini tidak dikerjakan karena tidak seui dengan kompetensinya. Dalam menjalankan pengobatan para batrra memakai berbagai ramuan jamu/ herbal serta menggunakan berbagai cara pengobatan fisik seperti bekam, refleksi, totok darah, totok kayu, doa/ rukyah serta menggunakan energi. hal ini sesui dengan pendapat Arjatmo (1992) battra adalah orang-orang yang dikenal dan diakui oleh masyarakat lingkungannya sebagai orang yang mampu dan melakukan tindakan pengobatan dalam rangka pelayanan kesehatan masyarakat dengan berbagai metode teknik pengobatan tradisional dan ramuan seperti terapi bekam, refleksi, tusuk jarum, totok darah, dan lainya serta yang menggunakan berbagai ramuan. Hal tersebut didukung dari pendapat Purwanto. B (2012) menyatakan pengobatan tradisional adalah pengobatan yang sudah dari zaman dahulu digunakan dan diturunkan secara turun temurun .para battra sudah memiliki pengalaman yang cukup panjang hingga dipercaya masyarakat untuk mengobati hingga saat ini mereka masih banyak diperya masyarakat yang datang berobat. Dari segi pengobatan yang dilaksanakan para batrra masih kurang memperhatikan kebersihan dan kenyamanan tempat praktek, serta para batrra hanya sedikit yang memiliki buku pedoman terapi jamu/atau buku pedoman pengobatan yang di pakai Semua battra dalam mengobati pasien menggunakan ramuan jamu/ herbal serta dikombinasikan dengan bahan lainya seperti madu, dan gula. Hal tersebut sesui dengan pengertian obat tradisional dari FOHAI (2011) obat tradisional adalah bahan atau ramuan bahan yang berupa bahan tumbuhan, bahan hewan, bahan mineral, sediaan sarian (galenik) atau campuran dari bahan tersebut yang secara turun temurun telah digunakan untuk pengobatan dan dapat diterapkan sesui dengan norma yang berlaku di masyarakat. Sedangkan berbagai bentuk sediaan yang diberikan pada pasien berupa : bentuk seduan/ godokan, bentuk instan, bentuk sirup, bentuk simplisia murni dalam kemasan plastik, berbentuk kemasan untuk wedang jamu dan ada yang berbentuk serbuk dalam kapsul. Selain bentuk bentuk sediaan diatas masih ada yang membuat ramuan dengan cara di fermentasi, dibuat seperti teh dari bahan jamu herbal serta dalam bentuk serbuk lulur. Tujuan para battra menggunakan berbagai bentuk penyajian adalah agar menarik dan membuat pasien mudah untuk meminumnya dan pasien percaya dengan jamu yang diberikan pada pasien. Hal ini sesui dengan FOHAI (2011) bentuk sediaan jamu yang paling disukai penduduk adalah cairan diikuti seduaan/ 
serbuk, rebusan/ rajangan dan bentuk kapsul atau tablet. Berbagai bentuk sediaan jamu yang dibuat para battra membuat penampilan jamu semakin menarik dan variatif walaupun cara pembuatanya masih sangat sederhana dan bersifat rumahan dan perlu pembinaan/ pengembangan untuk tarap kemanfaatan, kebersihan serta keamananya, agar masyarakat dapat terlindungi. Didapatkan 23 ramuan yang dipakai oleh para pengobat tradisional untuk mengobati penyakit yang sering terjadi dimasyarakat, antara lain: ramuan untuk penyakit asam urat, hipertensi, penurun kolesterol, penyakit gula atau diabitus militus, ambeyen, sakit kuning, peningkatan kesuburan, peningkatan stamina pria dan ramuan lainya, akan tetapi setiap jenis ramuan terdapat beberapa variasi isi komposisi ramuan setiap battra walaupun ada jenis ramuan yang bahan dasarnya sama, akan tetapi variasi dan jumlah ramuanya berbeda setiap battra, hal ini dimungkinkan karena masing masing battra memiliki pengetahuan dan pengalaman yang berbeda dan tidak memiliki pendidikan kesehatan tradisional yang sama, sehingga cara membuat ramuanpun berbeda, juga cara penyajianpun berbeda. Maka diperlukan pembinaan dari pemerintah untuk para battra agar memiliki ketrampilan dan pedoman peracikan jamu yang standar agar aman untuk masyarakat. Ramuan yang dipakai untuk pengobatan tersebut memiliki manfaat yang baik dan bahan rajikan ramuan dari para battra tersebut memiliki komposisinya tidak berbeda jauh/ mendekati indikasi obat herbal indonesia dalam Formularium Obat Herbal Asli indonesia (FOHAI) (2011) seperti herbal untuk hipertensi meliputi seledri, rosela mengkudu, pegagan, blimbing wuluh dan bawang putih. Herbal untuk dislipidemia meliputi: bawang putih, rosela, mengkudu, belimbing wuluh, kunyit dan temu lawak., herbal untuk hiperurisemia (asam urat) adalah sidaguri, anting anting, kepel, dan daun salam., herbal untuk diabitus militus : Pare, daun salam, jamblang, kelabet, kayu manis, brotowali, mengkudu, sambiloto, kunyit., herbal untuk paliatif penyakit kangker : sirsak, pegagan, kunyit putih, sambiloto, ceplukan manggis keladi tikus., dan lainya Ramuan yang dimiliki para battra ini juga memiliki kesamaan atau masuk dalam daftar tanaman untuk mengatasi gangguan kesehatan dari Pedoman Rasionalisasi Obat Tradisional vol 1 (2014) contoh tumbuhan obat untuk Hipertensi meliputi : daun alpukat, bawang, kumis kucing, mahkotodewo, mengkudu, pegagan, rosela blimbing wuluh, ketimun, meniran dan lainya. Tanaman utuk kencing manis:meliputi : daun alpukat, brotowli, daun sendok, jamblang, kayu manis, klabet. murbei, pare, sambiloto, salam dan lainya. Tanaman untuk kebugaran dan vitalitas meliputi : alang -alang, cabe jawa, secang, kencur, kunyit, jinten hitam, gingseng, purwoceng, pronojiwo, jahe, ketumbar, krangean dan lainya. Hasil penelitian ini juga didapatkan bahwa untuk mengobati satu penyakit yang sama akan tetapi setiap battra memiliki ramuan yang berbeda komposisi racikanya, tetapi didapatkan ada beberapa persamaan bahan racikan jamunya (simplisianya) hal ini terjadi karena memang diantara para battra tidak pernah saling bertukar informasi dan tidak pernah menyamakan ramuan pengobatannya dengan yang lain, dan itu merupakan rahasia masing masing battra dan ciri empiris mereka. Didapatkan 81 jenis tanaman yang dipakai para battra, 
terdiri dari 48 tanaman yang dimanfaatkan daunya, 10 tanaman yang dimanfaatkan adalah rimpangnya, 7 jenis akar-akaran, 6 jenis tanaman batang dan kulit, 6 jenis bunga dan buahnya, serta 4 jenis tanaman biji. Hal tersebut sesui dengan pendapat Hariana A.(2007) yang mengatakan bahwa tumbuhan obat merupakan potensi kekayaan yang perlu dilindungi karena dapat dimanfaatkan sebagai bagian pengobatan yang aman. hal tersebut selaras dengan pendapat Arisandi Y dan Andriyani Y (2008) yang mengatakan di indonesia penggunaan obat tradisional yang di kenal sebagai jamu telah meluas sejak zaman nenek moyang hingga kini dan terus dilestarikan sebagai warisan budaya. Selanyutnya dikatakan indonesia memiliki 30.000 species tanaman dan 940 species yang diketahui berkasiat sebagai obat atau digunakan sebagai bahan obat. Sedangkan 24 jenis tanaman herba yang dipakai daunya tersebut memang memiliki kasiat sebagai obat tradisional yang nyata karena tanaman tersebut terdaftar dalam jenis tanaman obat FOHAI (2011) sebagai obat herbal asli indonsia yang berkhasiat seperti daun kumis kucing dan sambiloto untuk pengobatan DM, seledri dan pegagan untuk pengobatan hipertensi, sidaguri, anting-anting, kepel dan salam untuk pengobatan asam urat dan lainya. Juga berbagai jenis daun dari jenis tanaman pohon seperti daun salam daun mimbo untuk mengobati penyakit DM, daun ungu untuk pengobatan ambeyen, daun jati belanda daun kemuning daunjati cina untuk hipertensi dan pengurus badan ,daun senggugu untuk batuk dan gurah dan lainya. Sedangkan daun dari tanaman rambat seperti daun brotowali untuk penyaki DM, daun sirih sebagai pereda nyeri dan anti septik, daun binahong penambah nafsu makan, dan lainya juga berkasiat obat yang terdaptar di FOHAI (2011) dan PRKOT (2014) vol 1. Tidak semua tanaman obat yang dipakai untuk mengobati adalah daunya, selain tanaman yang diambil daunya banyak tanaman yang dimanfaatkan adalah rimpangnya, Jenis akar-akaran, umbi dan biji - bijian juga banyak digunakan untuk membuat ramuan obat oleh para pengobat tradisionl antara lain akar alang alang, rumput teki, ubi dan lainya.

\section{KESIMPULAN DAN SARAN}

Penelitian tentang ekplorasi metode pengobatan tradisional oleh para pengobat tradisional di wilayah karesidenan Surakarta dapat disimpulkan sebagai berikut :Untuk mendeteksi gangguan kesehatan pada pasien para battra menggunakan berbagai metode antara lain : bertanya keluhan sakit dan riwayat penyakitnya, memeriksa bagian tubuh yang sakit, melihat : (wajah dan mata, warna kulit dan gejala ditelapak tangan), menotok jalan darah di leher, menggunakan energi serta melihat secara spiritual.dan ada juga battra yang memeriksa pasien dengan menggunakan bantuan alat seperti tensi meter, termometer, kamera digital dan laptop serta alat refleksi dari kayu. didapatkan 2 metode pengobatan yang di pakai para battra untuk mengobati pasien jaitu : a). menggunakan ramuan jamu/ herbal dan b).menggunakan ketrampilan fisik seperti : bekam, refleksi totok darah/ wajah, boreh terapi, rukyah serta menggunakan energi illahi. Didapatkan 23 jenis ramuan jamu yang dipakai para battra antara lain : ramuan untuk asam urat, penurun kolesterol, anti hipertensi, diabitus militus, ramuan kesuburan, peningkatan stamina, ambeyen, amandel, batu ginjal, sakit kuning ramuan untuk 
kangker dan lainya, sebagian ramuan ada kesamaan bahan, sebagian yang lain bervariasi bahan ramunya.adapun bentuk sediaan ramuan berupa seduan, godokan, sirup, jamu fermentasi, teh , instan, boreh dan kapsul. Didapatkan 81 Jenis tanaman obat yang digunakan para pengobat tradisional berupa daun dari tanaman jenis herba ada 24 jenis, daun dari tanaman pohon 18 jenis serta daun dari dari tanaman rambat 6 jenis. Selain para battra juga menggunakan tanaman jenis rimpang ada 10 jenis, batang tanaman dan kulit 6 jenis, bunga dan buah dari tanaman 6 jenis, akar dan ubi 7 jenis serta bijibijian. Saran Hendaknya para battra dapat berupaya terus menerus meningkatkan kemampuan dalam melakukan berbagai cara mendetksi gangguan/ penyakit pasien karena sebagian battra kurang mendalam dalam mengenal penyakit pasien agar tidak terjadi kesalahan memprediksi gangguan/ penyakit pasien, peran pemerintah daerah melakukan pembinaan sangat diperlukan karena selama ini belum pernah ada pembinaan pengetahuan/ ketrampilan para battra dari pemerintah daerah, yang tampak pemerintah melalui dinas kesehatan hanya memfasilitasi perijinan praktek battra. Peran organisasi ASPETRI juga diperlukan untuk pembinaan pengetahuan dan ketrampilan para battra. Bagi para battra yang menngunakan metode pengobatan dengan jamu hendaknya benar-benar memperhatikan kebersihan dan keamanan sejak dari penyiapan tanaman, pengolahan simplisia, peracikan, pembuatan jamu sampai penyimpanan, pemakaian serta penyajian/ distribusi ke pasien jamu harus memenuhi kaedah bersih, aman,bermutu dan berkasiat. Untuk mencapai hal tersebut juga diperlukan pembinaan dari pemerintah daerah dan organisasi profesi
ASPETRI. Sedangkan untuk para battra yang menggunakan pengobatan dengan memakai ketrampilan fisik hendaknya dilakukan dengan cara yang hati - hati jangan bersifat invasif dan selalu meminta persetujuan dari pasien atau keluarga setiap akan melakukan upaya ketrampilan fisik. Masing - masing battra yang menggunakan ramuan jamu/ herbal hendaknya memperhatikan tentang komposisi ramuanya agar saling sinergis dan mengguatkan, memperhatikan kasiat dan keamananya, sebaiknya ramuan yang dimiliki bila tidak berasal dari warisan turun temurun hendaknya disesuikan dengan komposisi ramuan yang sudah di saitifikasi agar kasiat dan keamananya terjamin bagi masyarakat. Para battra yang memanfaatkan tanaman yang ada disekitar lingkunganya, atau ditanam sendiri hendaknya diperhatikan kondisi tamanan kesehatan dan kesuburan tanaman, dibebaskan dari penggunaan peptisida apapun, tidak menanam atau mengambil tanaman yang ada di pinggir jalan, serta tidak merusak nya. Bila bisa menanam sendiri akan lebih baik bila benar- benar memperhatikan perawatan tanaman dan pengolahan paska panenya serta penyimpanan bahan panen. Membeli simplisia lebih baik dengan para penjual atau petani yang telah terpercaya bahwa benar- benar tidak memakai peptisida.

\section{DAFTAR RUJUKAN}

Arisandi dan Adriyani Y.(2008).Kasiat berbagai tanaman Obat untuk pengobatan, erka medika, jakarta

Republik Indonesia. 2014. Undang Undang Republik Indonesia No. 36 Tahun 2014 Tentang tenaga Kesehatan. Jakarta: Sekertariatan Negara. 
Roosita, K., Kusharto, C.M., Sekiyama, M., Ohtsuka, R., 2006. Penggunaan Tanaman Obat Oleh Pengobat Tradisional Di Desa Sukajadi Wilayah Curuk Nangka Bogor: Media Gizi dan Keluarga. [Jurnal].1:77-87.

Umar, Wadda' A. 2012. Bekam untuk 7 penyakit kronis. Solo. Thibbia.

Uliyah dan Hidayat AA( 20015)Ketrampilan dasar Praktek Klinik, Salemba Medika, Jakarta

Subandi, B.2002. Konsep Pengobatan Tradisional Menurut Primbon Jawa: Humaniora. [Jurnal]. No. 14:12-19.

Sugiono. 2009. Metode Penelitian Pendidikan Pendekatan Kualitatif dan $R \& D$. Bandung.

Alfabeta.

Sugiono. 2013. Metode Penelitian pendidikan pendekatan kualitatif dan $R \& D$. Bandung. Alfabeta.

Tansy, F.D. 2013. Persepse Pasien Non Tionghoa di Klinik Karang Asem Surabaya Terhadap Pengobatan Tradisional Tiongkok: Program Studi Sastra Tionghoa Universitas Kristen Petra,Siwalankerto. [jurnal]. No. 121-131.

Widodo, W. 2002. Bioteknologi fermentasi susu. Universitas Muhammadiya, Pusat Pengembangan Bioteknologi. Malang.

Wahyudin, M. 2005. Proses Pembuatan dan Analisa Mutu Yoghurt.Balai Besar Penelitian dan Pengembangan Pascapanen Pertania. Bogor. [Jurnal] No.11: 1. 